\title{
Sociopsychotechnological Predictors of Individual's Social Loafing in Virtual Team
}

\author{
Juneman Abraham, Melina Trimutiasari \\ Department of Psychology, Bina Nusantara University, Jakarta, Indonesia
}

\begin{abstract}
The rapid development of technology and the demands of the workers to be productive have made efficiency and effectiveness of virtual team collaboration is becoming increasingly urgent lately. Therefore, it is important to identify the variables undermining the efficiency and effectiveness. This study aimed to investigate the role of perceived usefulness, perceived ease of use, and perceived playfulness of online collaboration tool (as elements of technology acceptance) and xenophobia in predicting social loafing (at the individual level)-a social psychological phenomenon that shows the declining performance of the individual when working in the group. The contribution of this research is its attempt to combine social psychological and technological factors in explaining human performance in the context of the group when interacting with technology. The research design was correlational predictive, with multiple linear regression data analysis technique. Participants of this study were 80 students and employees (43 males, 37 females; mean of age $=25.58$ years of old, standard deviation of age $=4.92$ years) who work using online collaboration tool in a virtual team. The results showed that the perceived playfulness, perceived ease of use, and xenophobia were able to predict an individual's social loafing, but the perceived usefulness is not able to predict it. Implications of the results of research in order to prevent social loafing are stated in the Results and Analysis section.
\end{abstract}

Copyright (c) 2015 Institute of Advanced Engineering and Science. All rights reserved.

\section{Corresponding Author:}

Juneman Abraham, Department of Psychology,

Bina Nusantara University,

Jl. KemanggisanIlir III no. 45, Palmerah, DKI Jakarta 11480, Indonesia.

Email: juneman@binus.ac.id

\section{INTRODUCTION}

Virtual team is a team in which its works and interactions between their members are primarily mediated by information and communication technology (ICT) or does not occur face-to-face on a shared physical space in a certain frequency [1]. Gibson and Cohen [2] added that the virtual team has intricacy compared with offline/collocated team in four ways, namely (1) extensive diversity, (2) developmental idiosyncrasies, (3) the dynamic nature of work, and (4) technological complexity. Extensive diversity is an element that is almost inevitable in a virtual team. It is because the virtuality aspect allows the involvement of many people who have different social identities either on the basis of race, religion, socio-economical status, nationality, culture, profession, and other types of group, which brings different "tacit knowledge". This diversity brings to the next virtual team identifying mark that is developmental idiosyncrasies. It balances the interdependence level and the risk level out of a virtual team interaction, in order to bridge and coordinate the existing diversity. Reviewing from the nature of its work, the virtual team involves intensive 
dialogue or discussion, greater flexibility, and a more varied network structuring. The collaboration can take place either synchronously (real time) or asynchronously. Because virtual teams rely heavily on information technology as a means of its collaboration, and there is also a fact about the more increasing need for enriching communication and improving response, then the use of more advanced technology is something that is becoming more popular in the virtual team.Poole and Zhang [1] pointed out that virtual team members can exist in the same city (or even in the same building) and has a variation of the frequency degree in the physical meetings between themselves.

As a team, the virtual team still keeps the characteristics of a "traditional" team. Attributes of a team are (1) has a shared goal that is achieved through interdependence contributions of its members, (2) views the team itself as what is seen by other person or group as a social entity that has a high level of entiativity or teamness [3]-[4].Virtualityof a team, as formulated by Mihhailova [5], is a measurement of the multiplication between the richness of communication channels ("Can the used online channel maximize interaction of the five senses among team members?"), frequency of communication ("How often is the ICT used as the means of communication between members of the team?"), and time spent on communication ("How long is the ICT used in a team collaborative working?"). The higher score resulted from this multiplication, the higher virtuality of a team will be.

To achieve the shared goal of a virtual team, then the efficient and effective contribution of the entire team members is well required. Lewkowicz, Wijnhoven, and Draghici [6] indicated that the collaborative work of the virtual team is a process involving cognitive aspects (members' capability) and affective aspects (with the members motivating each other). Very often it is not easy because in factual there is a heterogenous background of its members. In the group psychology, there are symptoms that are counterproductive toward the group collaboration; one of them is social loafing. Social loafing is "the tendency of members to do less than their potential, as a particularly serious problem plaguing groups" [7]. Social loafing is indeed found in a virtual team [8-10]. Social loafing is a kind of application of game theory. It involves a decision by someone to do a defection or cooperation in the group that takes into account about the motivation of the other members of the group [11]. Symptoms of social loafing on the virtual team described by Turel and Zhang [12] are as follows: "Social loafing in virtual teams may be executed through silence (e.g., a team member who waits for others to generate their inputs, hoping that they will be sufficient) or result in undelivered promises (when a team member promises to do something but does not)."

Chidambaram and Tung [7] found that the group member dispersion and the group size affect social loafing in technology-supported groups, while also realizing (after a literature review) that the following factors also play roles on the group performance: an evaluation toward the members performance, gender, the complexity of the task, coworkers hope, and culture. Based on those descriptions, it appears that social loafing is a construct contrary to the participation in an online group such as virtual team. Online participation is a part of the processes that occur in a virtual team [1], [13], which shows the work dynamics of the virtual team in achieving its goals. In his literature studies, Martins et al. [13] found that the following factors are related to the online participation: personality (extraversion), flexibility of participation schedule, perceived equality, collaborative conflict management style, technical skills, tolerance toward technical uncertainty, and trust. Piezeon and Ferree [8] found that perceived distributive justice is negatively correlated with social loafing in online learning groups, while the perception of the dominant behavior of group members is positively correlated with social loafing. Beenenet al. [14] found that the level of goal specificity and the perception saliency about the uniqueness of individual's contribution to the group's performance will degrade the online social loafing. Sin [10] found that media richness is positively correlated with the motivation and efficiency of decision-making of the virtual team members. Hoisl, Aigner, and Miksch [15] found that social rewarding system thatis embedded in the Wiki can increase the community participation in contributing and editing articles.

As shown above, researches on online social loafing are much focused on (1) characteristics of the group task, (2) characteristics of the group members, (3) characteristics of the interaction between members of the group, and (4) characteristics of the technology/systems. Studies that identified predictors of social loafing on a virtual team was not touching very much on human interaction with technology (in this case: an online collaboration tool; OCT), whereas the use of technology is one of the distinctive features of the virtual team, and it is an integral layer to the work contribution of virtual team members. Nevertheless, there were few studies that focused on those interactions. For example, Turel and Connelly [16] found that the higher of a person's psychological collectivism, the higher the perceived usefulness of the OCT in the eyes of the peoplewill be, which will increase his/her intention to use the OCT. The reason is that the person sees the technology to be useful to optimize the collective works of his team. Turel and Zhang [12] found that an individual's perception about the social loafing occurrences in his/hervirtual team will cause the perceived usefulness of the OCT decreased in him/her, and hence lowering his/her intention to use the OCT. 
This present study is different from the researches conducted by Turel and his colleagues [12], [16] because it examined the influence of technology acceptance model (TAM) [17] dimensions toward the online social loafing at the individual level in a more comprehensive way. TAM is a model that explains the motivation of the technology users, and it is also able to predict whether the user will actually use or reject a system [18]. TAM dimensions applied in this study were regarded as predictors of social loafing in a virtual team. TAM can be used to intervene in order to maximize the work productivity that adopts the technology by encouraging behavioral intention of the individual to use the technology [19]. To the authors' knowledge, there have been no studies that specifically link the TAM aspects with individual's social loafing. In this present study, the authors proposed that if an individual does not have a positive attitude and/or high intention to use online collaboration tool, it is difficult to expect fluency, contribution, and effective effort in the collaboration of the virtual teams. In other words, laziness or social loafing will have a very big chance to happen. The variable investigated in this research is not only perceived usefulness, but also perceived ease of use, and perceived playfulness of technology (online collaboration tool). This study also has different direction compared with the research of Turel and Zhang [12]. It did not examine the predictive power of collective social loafing on perceived usefulness of technology but rather the predictive power of the perceived usefulness on the individual's social loafing.

Based on a review of several literatures [17], [20]-[25], the elements of TAM in this study are defined as follows: (1) Perceived usefulness (performance expectancy) is the degree to which the user believes that using a particular technology will improve the performance; (2) Perceived playfulness (hedonic/intrinsic motivation) is the degree to which an individual perceives that the attention is focused on his/her interaction with technology; have curiosity throughout the interaction, and found that interaction with the technology is pleasant (enjoyable) or interesting, so that he/she became sticky, very much involved, attracted, engrossed in the technology, even being lost of him/herself; (3) Perceived ease of use (effort expectancy) is defined as the degree to which users believe that the use of technology would be free of effort, that technology is controllable, obvious, and understandable. This study hypothesized $(\mathrm{H} 1, \mathrm{H} 2, \mathrm{H} 3)$ that the higher the perceived usefulness, perceived playfulness, and perceived ease of use of the OCT, the lower the individual's social loafing in a virtual team will be.

The second variable that is selected by the author as a predictor of social loafing in a virtual team is xenophobia. Xenophobia is the "fear of strangers or of the unknown or of anything that is different" [26]. By using the concept of social categorization and social identity ("us versus them"), Walker [26] and Rydgren [27] stated that the xenophobia caused prejudice (negative attitude) and discrimination (including violence) against outgroup members that were dissimilar biopsychosocially. The targetted outgroup may have one or more different bases as follows: gender, sexual orientation, race, nationality, regionality, politics, religion, ideology, social class, or other fixed factors [26]-[29]. Kivisto [28] added that xenophobia emphasized the dimension of "emotional reaction to other", in order to not focus on cognitive aspects. However, Adler [29] stated that the reaction is actually firstly the one of the collectivity in which individual member of the group onlyreproduces it.

By using the evolutionary psychology approach, it is known that xenophobia is a universally specific feature in human inherited through human history, and appeared in human behavior favoring interaction with ingroup members [28]. Adler [29] reinforced this explanation by stating that xenophobia is a psychological mechanism that is built up in the history of the adaptation process to survive by strengthening the ties of kinship. However, this theoretical approachhas been denied recently by the finding that xenophobia is the result of social construction because (1) some cases show that xenophobia can be managed constructively so it does not generate fear and hatred [28], and that (2) xenophobia is more functional to ensure solidarity and social cohesion [29]. In addition, Rydgren [27] stated that hostiles on the xenophobic persons will be activated and done if the outgroup "are believed to threaten the identity (beliefs, practices, mores, and traditional values) or the material interests of the in-group."Thus, according to Rydgreen [27], xenophobia is a fear and hatred toward the unwanted strangers which is the result of social perception. As mentioned above, extensive diversity is one of the features which make the virtual team to be more complicated. The diversity of the cultural contexts, including languages and the emotion expressions, can naturally create a potential shock and conflict among group members [1]. By combining this knowledge with various previous explanations, this study hypothesized (H4) that the higher levels of xenophobia in a person, the higher the individual's social loafing in a virtual team will be.

When it is described in a hypothetical chart, then the framework of this study is as shown in Figure 1. The entire predictors are hypothesized to beable simultaneouslypredict an individual's social loafing (H5). The framework shows that social loafing in virtual teams is a sociopsychotechnological matters, which involves human aspects (xenophobia) and human-technology interaction (technology acceptance model's components).

IJECE Vol. 5, No. 6, December 2015 : $1500-1510$ 


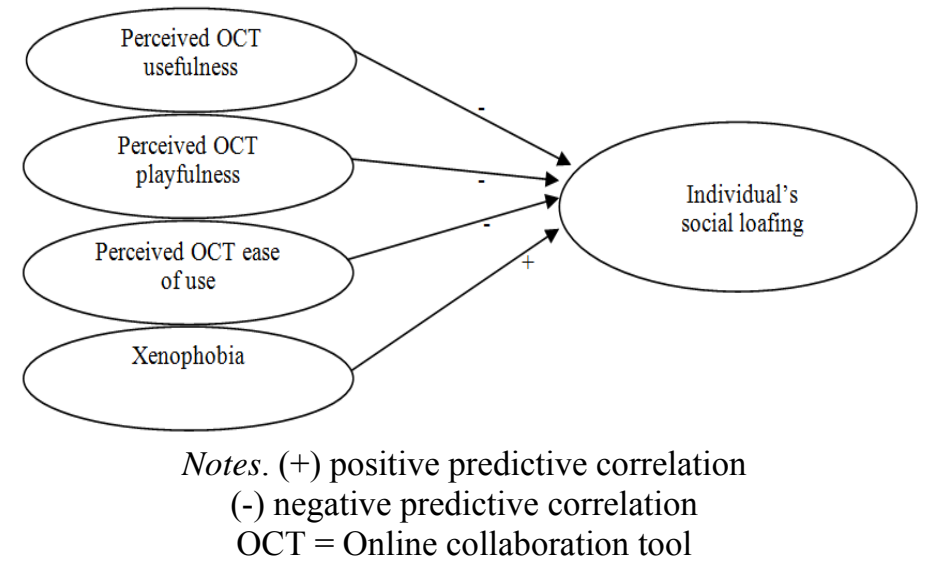

Figure 1. The hypothetical model

\section{RESEARCH METHOD}

\subsection{Participants and Design}

Participants of this study were 80 employees and students (43 males, 37 females; mean of age $=$ 25.58 years of old, standard deviation of age $=4.92$ years) who work or study in companies or universities in Special Capital Region of Jakarta, the capital city of Indonesia, and in the surrounding areas (Bogor, Depok, Tangerang, Bekasi). Those who met the criteria of working in the virtual teams, whether they are involved in synchronous or asynchronouswork with other virtual team members, were recruited by purposive sampling technique to be the sample of this study. To test the reliability and validity of the measurement instrument, this study recruited 60 employees and students besides the field research participants in the instrument try-out phase.

The design of this study was predictive correlational design with multiple linear regression data analysis technique. Predictor variables in this study are the perceived usefulness of OCT, perceived playfulness of OCT, perceived ease of use of OCT, and xenophobia. Criterion variable in this study is the individual's social loafing in virtual team.

\subsection{Materials and Procedure}

Participants were given a questionnaire consisting of some psychological scales in Indonesian. The criteria for determining the reliability is the index of internal consistency (Cronbach's Alpha $\geq 0.600$ ). The criteria for determining the validity of scale items are the index of corrected item-total correlations $\geq 0.250$.

Psychological scale measuring individual's social loafing in a virtual team is adapted from George [30]. This measurement instrument consists of 10 items with response options ranging from "Strongly Disagree"(score of 1) to "Strongly Agree" (score of 6). The preliminary information on this scale is as follows:"Virtual Team is a group that has a purpose or goal enabling the members work together online using devices of information and communication technologies (ICT) such as wide area networks, video conference, e-mail, instant messaging, and so forth, whether the individuals are only separatedby room or continent. When I was working with the virtual team, then I would .... " The examples of items of this scale are: (1) I deferred responsibilities I should assume to other virtual team members, (2) I put forth less effort when other virtual team members existed or were able to do the work, (3) I spent less time working on the project if other virtual team members were available, (4) I gave less effort than other virtual team members, (5) I avoided performing additional tasks in the project as much as possible, (6) I underestimated the work and let the other virtual team members worked on it, and (7) I was likely to volunteer to do a task if another virtual team member available or were able to do the work.Reliability and validity testing showed that the index of Cronbach's Alpha is 0.778 with the corrected item-total correlations ranged from 0.302 to 0.671 , without any item that needs to be aborted.

Psychological scale measuring perceived OCT usefulness was adapted from the Revised Scale for Perceived Usefulness [18] which was modified from Davis [31]. This measurement instrument consists of 10 items with response options ranging from "Strongly Disagree" (score of 1) to "Strongly Agree" (score of 6).

The initial information of perceived usefulness, playfulness, and ease of use technology is: "Online collaboration tools are equipment that allow a group of people to cooperate or collaborate online and to exchange ideas without being in the same room and/or at the same time. Examples of online collaboration tool: Video conferencing (Skype, VSee, etc.), teleconferencing, web conferencing (Adobe Connect, Click

Sociopsychotechnological Predictors of Individual's Social Loafing in Virtual Team (Juneman Abraham) 
Meeting, etc.), instant messaging (Yahoo Messenger, eBuddy, Hangouts, Skype, etc.), collaborative writing (Google Drive, Primary Pad, Zoho Docs, etc.), document sharing (Adobe Acrobat, Google Drive, etc.)."

The examples of items of perceived OCT usefulness scale on this research are: (1) Using online collaboration tool improves the quality of the work I do, (2) Using online collaboration tool gives me greater control over my work, (3) Online collaboration tool enables me to accomplish tasks more quickly, (4) Online collaboration tool supports critical aspects of my job, and (5) Overall I find the online collaboration tool useful in my job. Reliability and validity testing showed that the index of Cronbach's Alpha is 0.951 with the corrected item-total correlations ranged from 0.650 to 0.893 , without any item that needs to be aborted.

Psychological scale measuring perceived OCT playfulness is adapted from the Perceived Enjoyment Scale [32] and the Perceived Playfulness Scale [33]. This measurement instrument consists of 10 items with response options ranging from "Strongly Disagree" (score of 1) to "Strongly Agree" (score of 6). The examples ofitems of perceived OCT playfulness scale in this study are: (1) When interacting with the online collaboration tool, I am not aware of the time as it elapses, (2) When interacting with online collaboration tool, I am not aware of distracting noise, (3) Using online collaboration tool involves in the enjoyable process, (4) Using online collaboration tool is interesting, (5) Using online collaboration tool is a good way to spend my leisure time, and (6) A variety services in online collaboration tool arouse my curiosity. Reliability and validity testing showed that the Cronbach's Alpha index is 0.822 with the corrected item-total correlations ranged from 0.277 to 0.761 , with 2 items aborted from the scale.

Psychological scale measuring perceived OCT ease of use was adapted from the Revised Scale for Perceived Ease of Use [18] which was modified from Davis [31]. This measurement instrument consists of 10 items with the response options ranging from"Strongly Disagree" (score of 1) to "Strongly Agree" (score of 6). The example of items of perceived OCT ease of use scale in this study are: (1) I find it cumbersome to use the online collaboration tool (unfavorable item, the response was reversely coded: ' 1 ' to be ' 6 ', ' 2 ' to be ' 5 ', ' 3 ' to be ' 4 ', ' 4 ' to be ' 3 ', ' 5 ' to be ' 2 ', and ' 6 ' to be ' 1 '), (2) Learning to operate the online collaboration tool is easy for me, (3) The online collaboration tool is rigid and inflexible to interact with (unfavorable item), (4) It is easy for me to remember how to perform tasks using the online collaboration tool,(5) Interacting with the online collaboration tool requires a lot of my mental effort (unfavorable item), (6) My interaction with the online collaboration tool is clear and understandable, (7) I find it takes a lot of effort to become skillful at using online collaboration tool (unfavorable item). Reliability and validity testing showed that the index of Cronbach's Alpha is 0.883 with the correlations of corrected item-total ranged from 0.428 to 0.769 , without any item that needs to be aborted from the scale.

Psychological scales measuring xenophobia was adapted from Van der Veer et al. [34]. This measurement instrument consists of 9 items with response options ranging from "Strongly Disagree" (score of 1) to "Strongly Agree" (score of 6).The preliminary information on this scale is as follows: "The definition of 'stranger' is people whose ethnicityand/or religion and/or race and/or nationality is/are different from yours. What is meant by the 'network' or the 'networking' is any person or group that is connected with you, or any activities of connecting with others". The example items of this scale: (1) The existence of strangers causes increase in crimes, (2) Strangers take jobs from people who are here already in my network, (3) Interacting with strangers makes me uneasy, (4) I worry that strangers may spread unusual behavioral disorders, (5) I worry that in case of war or political tensions strangers will be loyal to their social network or group of origin, (6) With increased number of strangers I fear that out way of life will change for the worse, (7) I doubt that strangers will put interest of my social groups in my social network first, and (8) I am afraid that my own culture will be lost with increase in movement of strangers in to my social network. Reliability and validity testing showed that the Cronbach's Alpha index is 0.866 with the correlations of corrected itemtotal ranged from 0.412 to 0.759 , with 1 item aborted from the scale.

\section{RESULTS AND ANALYSIS}

Demographic characteristics of the participants are as follows: The level education of the participants were: senior high school (18), Diploma/D3 (2), Bachelor (59), and Master (1). Most participants (65) were private employees, 2 people were civil servants, and 13 people were students. The types of work involved in the virtual team include project audit, online learning officer, system analyst, system engineer, software developer, web builder, business analysts, graphic designer, human resources staff, IT helpdesk, telecom officer, and junior consultant. On students, virtual team occurs in the processing of course assignments or the work related witha student organization. On the employees, working experience durations of the participants is: 0-1 year (17), 2-5 years (30), 6-10 years (3), and the rest do not tell their working duration.

The classical assumption of regression test showed that the data is normal, and free from heteroscedasticity and multicollinearity. Multiple linear regression analysis showed the results of $F(4,79)=$ 
4.806, $p=0.002, R^{2}=0.204$. This means that the entire predictors simultaneously have contributions of $20.4 \%$ on the high and low level of an individual's social loafing. Thus, H5 was supported by the empirical data.

More specifically, perceived playfulness $(\beta=-0278, p<0.05)$ and perceived ease of use of OCT $(\beta=$ $-0.374, p<0.01$ ) are able to predict individual's social loafing in the negative direction (see Table 1 ). This means that the higher the perceived playfulness of the OCT, the lower of the individual's social loafing will be. The higher the perceived ease of use of OCT, the lower of the individual's social loafing. Thus, H2 and H3 were supported by the empirical data.

Xenophobia $(\beta=0.240, p<0.05)$ is able to predict an individual's social loafing in a positive direction. This means that the higher the xenophobia level in a person, the higher the individual's social loafing will be.Thus, $\mathrm{H} 4$ was supported by the empirical data.

Perceived usefulness of OCT $(\beta=0.270, p>0.05)$ is not able to predict an individual's social loafing. Thus, H1 was not supported by the empirical data.

Table 1. Multiple linear regression analysis predicting Individual's Social Loafing $(n=80)$

\begin{tabular}{lrrrrr}
\hline \multicolumn{1}{c}{ Predictor } & \multicolumn{1}{c}{ B } & \multicolumn{1}{c}{ SE B } & \multicolumn{1}{c}{$\beta$} & \multicolumn{1}{c}{$t$} & \multicolumn{1}{c}{$p$} \\
\hline Perceived usefulness of OCT & 0.228 & 0.124 & 0.270 & 1.841 & 0.070 \\
Perceived playfulness of OCT & -0.332 & 0.165 & -0.278 & -2.009 & 0.048 \\
Perceived ease of use of OCT & -0.327 & 0.110 & -0.374 & -2.977 & 0.004 \\
Xenophobia & 0.195 & 0.094 & 0.240 & 2.074 & 0.042 \\
\hline
\end{tabular}

Note: $R^{2}=0.204 ; S E=$ standard error; OCT $=$ online collaboration tool

Negative predictive correlation between perceived playfulness of the OCT and the individual's social loafing can be understood. A cooperation activities in the virtual world using virtual devices, such as OCT, will be an activity that is "dry" and "flat", as stated by Fiedler [35]. In this activity, people lost a lot of opportunities to establish shared values, trust, shared expectation, and social similarity in the midst of virtuality situation that eliminates "converging on similar rates and syntactic complexity, mimicry, warmth, and attentiveness" and touch ("trust needs touch"; Handy, as cited in [36]), which is usually found in face-toface interaction. Therefore, it is no wonder that, according to the results of the empirical research this time, one of the important things to make a social loafing decreasing is perceived playfulness of OCT. This finding implies that companies or other institutions using the OCT which desire to build and develop better teamwork needs to invest more in construction or adopt OCT design environment that is fun, pleasurable, enjoyable, engageable, and cause flow experience, as one of the main elements of the perceived playfulness [20]. Csikszentmihalyi (as cited in [37]) and Jin [38] stated that the flow experience is the result of interaction between the challenging activities and the individuals who try to answer the challenge by his/her skills. When it is applied to the use of technology for the cooperation of a team, the challenging activity must first be generated by technology such as OCT, so that OCT is able to build (1) the freedom to suspend reality, (2) intrinsic motivation, (3) internal control over the technology, and (4) arousal of exploratory behavior [39].

Such OCT example is Second Life (www.secondlife.com), which has a principle of "a freeing of the imagination" [40] and has a "richer channels to augment conversation" [41]. Perceived playfulness makes someone to actively involve themselves in the use of OCT, and this is the first layer that psychologically must be passed in order to collaborate with other virtual team members who also use the OCT. If one feels reluctant of using OCT, then the good team cooperation can not be expected at all.

This study found that perceived ease of use (PEOU) of the OCT is able to predict an individual's social loafing in the negative direction. In the context of a virtual team collaboration, PEOU turned out to play a much more important role than the perceived usefulness (PU) of OCT, and has a direct predictive correlation with the working performances of a team that use the OCT.This finding is not in line with the finding of the majority of studies (as cited in [42]) which found that perceived usefulness has a significant and larger effect size than the PEOU (in terms of behavior to adopt technology), and that it should affect firstly the perceived usefulness before it influences the attitudes toward-and the intention to use-the technology. However, a meta-analysis of the results of studies conducted over 15 years by Yousafzai et al.[42, p. 299] showed that for students and participants in experimental studies (instead of field studies in real organizational settings), "PEOU was found to be more important than PU in determining the attitude (toward technology usage)". They explained this finding by stating that for students, perceived usefulness is not defined by the students themselves but by his/her institution/college, so the perceived usefulness is not important for them; whereas for the laboratory experiment participants, their performance is being measured by the time criteria, so that PEOU is felt more important than the perceived usefulness because they have to demonstrate an efficient performance.

Sociopsychotechnological Predictors of Individual's Social Loafing in Virtual Team (Juneman Abraham) 
This present study provides extensions to the meta-analysis findings because this study was conducted in organizational settings through field surveys, but with additional features, i.e., what is being assessed is one's perception of his/her performance when cooperating with others within ann online group. Nowlan [43] reported his research results that groups having lower PEOU show worse performance than the groups that have higher PEOU. He explained that the group with a low PEOU will be busy in struggling, modifying the technology itself, making it less capable to direct its attention to group tasks that use the technology, and lose many opportunities to learn new skills using the technology. Furthermore, coping poorly to the difficulty of using the technology also reflects the poor conflict management skills and substandard performance management within the group [43]. On the other hand, in the higher PEOU team, higher comfort resulted from the use of technology could experience generalizations such as comfort in collaborating in the virtual teamwork. The implication of this finding is that (1) the OCT should be designed and/or modified from the beginning facets of the online collaboration implementation; the OCT should be designed in such away that it has high usability or, in other words, it does not require complex learning to use it; while from the user side, (2) OCT usage self-efficacy needs to be improved so that the individual's social loafing becomes lower.

Perceived usefulness of OCT is found to not be able to predict an individual's social loafing. This may be caused by the presence of two natures of perceived usefulness in relation to social loafing, which can be "beneficial" (has positive direction) and "harm" (has negative direction), so it appears having no correlation. Perceived usefulness in a person is able to bring a contentment feeling to the technologies that can meet the needs of productivity, efficiency, and performance so that people would constantly use the technology [44]-[45]. The intention of using OCT faithfully which is generated by the perceived usefulness is an indispensable condition for the occurrence of a virtual team collaboration. However, the level of perceived usefulness turns out to be also correlate with the social and cultural context in various directions [46]. For example, degree of industrialization and degree of religiosity are positively correlated with the perceived usefulness of information technology; while the degree of social inequality, individualism, and uncertainty avoidance are negatively correlated with the perceived usefulness.

Other researches found that social loafing is also influenced by social-cultural context [47]-[49]. Although these studies occurred in the offline setting or face-to-face. The results of these previous studies, when they are in interaction with one another, imply that the socio-cultural context may contribute to mediate the relationship of predictive correlation beween perceived usefulness and the individual's social loafing, although this conjecture requires further testing. If the hypothesis is supported by empirical data on subsequent research, the thesis produced will be the extension of the co-construction theory [50]-[51], which has the proposition that the things happen in offline world also occurs in the online world. In addition to the description set forth above, the lack of predictive correlation between the perceived usefulness of the OCT and the individual's social loafing might also be caused by the ambigous interpretation of "usefulness", that "usefulness" itself which has a taxonomy, in which this construct contains the component(s) about what, in a user's mind, makes a technology-based tool or system useful [52].

Perceived usefulness was also found to be negatively correlated with technology usage [53]-[54]. Particularly in the context of e-collaboration technology, Dasgupta et al. [54] explain that the negative correlation is due to the gap, in their research participants, between perception and actual condition of the usefulness of the technology they face, and this gap is also different in terms of its magnitude between novice and expert users. Beside we need to pay attention to the consonanceor dissonance between perceived and actual usefulness, we also need to consider seriously that a group is a gestalt, in which its behavioral tendency can not be predicted solely based on the sum of individual's behavioral tendencies of the members [55]-[56]. Lewin (as cited in Forsyth [57]) stated that "A group is a Gestalt-a unified system with emergent properties that cannot be fully understood by piecemeal examination when individuals merged into a group something new was created and that the new product itself had to be the object of study". This means that group members' perceived usefulness of OCT might not be synonymous with the group's perceived usefulness of OCT.

The complexity of the perceived usefulness construct, as well as the antecedents and consequences that surround this construct, implies that we cannot assume, a priori, that the technology (including OCT) that is perceived as useful by the individual members of a team will automatically improve the overall performance of the team. This is one of the original contributions of this study that calls attention of decision makers in organizations implementing technologies. Based on these discourses, they need to think of at least three multi-level phases which might deliver the perceived usefulness effects of OCT on the social loafing (or group performance), namely individual's psychological dynamics (dissonance between perceived and actual usefulness), group dynamics, as well as the dynamics of the socio-cultural context that influence individual and virtual team as a whole.

IJECE Vol. 5, No. 6, December 2015: $1500-1510$ 
Xenophobia is found to be able to predict an individual's social loafing in a positive direction. The higher the xenophobia level in a person, the higher the individual's social loafing when using OCT. In organizations optimizing the OCT and virtual works where encounters between team members from different culturesoften become inevitable, xenophobia or prejudice towards strangers will obviously make a cooperation to be hard or complicated. Prejudice in the virtual environment makes a person keeping a distance in social interaction or avoiding others, either because they feel threatened of their identity or because they fear of judgment or negative appraisal or evaluation from others [58]-[59]. Avoidance or behaviors of keeping an interpersonal/social distance are caused by the social anxiety that create defensive behavior, both verbal and nonverbal, which is not favorable for a fair cooperation using OCT between virtual team members. Although a person is working in a virtual team where signs of the body either verbal or nonverbal are much eliminated, but the person's representation as "avatar" in the virtual environment can display spontaneous or automatic defensive reactions in the forms of position, orientation, direction and motion speed (for example, slow down, stay away), as well as the time spent by avatar (e.g., stay shorter) within a particular virtual social space against other avatars [59], similar to what happens in offline social environment. This explanation also has a biological basis, namely the activation of amygdala, sub cortical parts of the brain associated with negative emotions, that occurs when a person has a stereotype, prejudice and discriminative tendencies against the appearance of people who are considered as stranger or "different people" coming from other social categoriesthat different from himself/herself [58]. The implication of these findings is that the OCT need to be designed such a way that the avatars displayed does not trigger the feelings of threatened in anyone.

Avatar is an extension of our physical body, such as text, icon, and graphic, which can undergo restoration, escaping, improvement, and reworking in the virtual world [60]-[61]. The assumptions of a careful avatar design in a virtual team work context mentioned above is that "social interactions and social relations can be encoded in images" (Kress \& van Leeuwen, as cited in [62]). Avatar, that is a virtual self and that can be selected or even created by the subject (such as OCT user), interact and communicate with other avatars/selves. The communication and interaction occur also in the cooperation among virtual team members. In this avatar creation, in order to anticipate the adverse effects of xenophobia against a virtual team performance, then, in line with the results of this study, the avatars in the OCT need to be designed in such a way so that the form/appearance, gestures, and the style represent the ownership of socially preferable traits, and not strengthen negative stereotypes that are harmful to the any social groups of the team members (e.g. [63]). Nonetheless, the policy of an organization where OCT is used should also not restrain freedom of user in imagining, constructing, and expressing avatar that reflects the online identity and presence of him/herself in the virtual environment.

In the OCT that enables richness in the design and development of avatars, for example OCT using virtual reality (e.g. Second Life), the aspects that need consideration in designing an avatar in a situation of "conceptual tensions" mentioned above is "the way avatars look, what they can do, the way they can be used for communication, the context in which they are created, how many avatars can be created and in under what kind of governance, who owns the avatar, and how to plan avatar design"[61]. These considerations are important to be noted (especially in very diverse environments in which xenophobic attitudes are estimated to be more easily triggered) because after all, the avatar includes social expectations and social critiques [61], and it is important to achieve a condition of interpersonal trust in interacting avatars [64] in a virtual teamwork using the OCT. Precisely, trust in this context is [64]: “... anticipated cooperation .... Cooperation here should be understood as a behavior (or choices between courses of action) that is beneficial to someone else. Thus, trust is present to the extent that somebody acts in a way that implies an expectation of future cooperation from someone else".

Trust is an element that is a must in virtual teams where the achievement of the group is generated by the performance of its members which interdepends each other. Therefore, an organization that uses OCT can invite experts of various disciplines, such as psychology, linguistics, anthropology, communication science, semiotics, and sociology [60], [62], not only ICT experts, to design OCT environment that supports trust and reduces the negative impact of xenophobia.

\section{CONCLUSION}

This study concluded that social loafing-in the individual level-occuring in the virtual team collaborations can be predicted by xenophobia and two of the three components of technology acceptance, namely perceived playfulness and perceived ease of use of online collaboration tool. The research finding indicates that social loafing is not only contributed by the group and task dynamics (as found in previous studies), but firstly, before all, by the dynamics within the individual that interact with the OCT technology 
(perceived playfulness and perceived ease of use) and the dynamics of the attitudinal predisposition that interact with the social world (xenophobia).

Online context on a virtual team collaboration and the engagement of the sociopsychotechnological variables mentioned above are indeed the contribution of this present study compared with other "traditional" studies on social loafing, which mostly discussed it in the context of the offline world. The authors emphasize that in research on social loafing, human is not enough to be analyzed separately from the used technology. However, research on social loafing in a virtual team will be more comprehensive when it is integrating the findings of existing studies (e.g. task characteristics, types of virtual team cooperation, duration and frequency of online collaboration, types of members, and cultural diversities) with the variables involved in this study. This study is also limited in terms of the number of recruited samples. This is because at the time this study was conducted, it is quite hard to gain access and permission of the companies or other organizations whose members carry out the most virtual collaborations.

This study can be positioned as a precondition of the application of the previous research results which seeks to build efficient and effective social interactions, such as in a shared learning process [65] and in citizen engagement for prevention of cyber crime [66].

\section{REFERENCES}

[1] M. S. Poole and H. Zhang, "Virtual Teams," in The Handbook of Group Research and Practice, S. A. Wheelan, Ed. Thousand Oaks: SAGE Publications, pp. 365-385, 2005.

[2] C. B. Gibson and S. G. Cohen, "The Last Word: Conclusions and Implications," in Virtual Teams That Work: Creating Conditions for Virtual Team Effectiveness, C. B. Gibson, and S. G. Cohen, Eds San Francisco: John Wiley \& Sons, Inc., pp. 403-421, 2003.

[3] S. G. Cohen and D. E. Bailey, "What Makes Teams Work: Group Effectiveness Research from The Shop Floor to The Executive Suite," Journal of Management, Vol. 23, pp. 239-290, 1997.

[4] J. R. Katzenbach and D. K. Smith, "The Discipline of Teams," Harvard Business Review, Vol. 71, No.2, pp. 111120, 1993.

[5] G. Mihhailova, "From Ordinary to Virtual Teams: A Model for Measuring the Virtuality of A Team Work," in Proceedings of the Frontiers of e-Business Research Conference, 2006.

[6] M. Lewkowicz, F. Wijnhoven, and A. Draghici, "Misunderstandings in Global Virtual Engineering Teams: Definitions, Causes, and Guidelines for Knowledge Sharing and Interaction," in Methods and Tools for Effective Knowledge Life-Cycle-Management, A. Bernard and S. Tichkiewitch, Eds. Heidelberg: Springer-Verlag, pp. 145$157,2008$.

[7] L. Chidambaram and L. L. Tung, "Is Out of Sight, Out of Mind? An Empirical Study of Social Loafing in Technology-supported Groups," Information Systems Research, Vol. 16, No. 2, pp. 149-168, 2005.

[8] S. L. Piezon and W. D. Ferree, "Perceptions of Social Loafing in Online Learning Groups: A Study of Public University and U.S. Naval War College Students," International Review of Research in Open and Distance Learning, Vol. 9, No. 2, pp. 1-17, 2008.

[9] J. Suleiman and R. T. Watson, "Social Loafing in Technology-Supported Teams. Computer Supported Cooperative Work," Vol. 17, pp. 291-309, 2008.

[10] K-H. P. Sin, "Social Loafing in Virtual Collaborative Decision Making: Relationship among Media Richness, Media Synchronicity, Group Performance, and Individual Effort," Ph.D. dissertation, Walden University, 2010.

[11] S. L. Piezon, "Social Loafing and Free Riding in Online Learning Groups," Ph.D. dissertation, College of Communication and Information, The Florida State University, 2011.

[12] O. Turel and Y. J. Zhang, "Should I E-collaborate with This Group? A Multilevel Model of Usage Intentions," Information \& Management, Vol. 48, pp. 62-68, 2011.

[13] L. L. Martins, L. L. Gilson, and M. T. Maynard, "Virtual Teams: What Do We Know and Where Do We Go From Here?," Journal of Management, Vol. 30, No. 6, pp. 805-835, 2004.

[14] G. Beenen, K. King, X. Wang, K. Chang, D. Frankowski, P. Resnick, and R. E. Kraut, "Using Social Psychology to Motivate Contributions to Online Communities," in Proceedings of the 2004 ACM Conference on Computer Supported Cooperative Work, CSCW’04, Chicago, Illinois, USA, pp. 212-221, 2004.

[15] B. Hoisl, W. Aigner, and S. Miksch, "Social Rewarding in Wiki Systems - Motivating the Community," in Online Communities and Social Comput, HCII,Lecture Notes in Computer Science, vol.4564. D. Schuler, Ed. Berlin Heidelberg: Springer-Verlag, pp. 362-371, 2007.

[16] O. Turel and C. E. Connelly, "Team Spirit: The Influence of Psychological Collectivism on the Usage of ECollaboration Tools," Group Decision and Negotiation, Vol. 21, pp. 703-725, 2012.

[17] F. D. Davis and V. Venkatesh, "Toward Preprototype User Acceptance Testing of New Information Systems: Implications for Software Project Management," IEEE Transactions on Engineering Management, Vol. 51, No. 1, pp. 31-46, 2004.

[18] M. Y. Chuttur, "Overview of the Technology Acceptance Model: Origins, Developments and Future Directions," Working Papers on Information Systems, Indiana University, USA: Sprouts, Vol. 9, No. 37, 2009.

[19] V. Venkatesh and H. Bala, "Technology Acceptance Model 3 and a Research Agenda on Interventions," Decision Sciences, Vol. 39, No. 2, pp. 273-315, 2008.

IJECE Vol. 5, No. 6, December 2015: 1500-1510 
[20] M. Roringpandey and Juneman. "Masih Rekatkah Kita Dalam Bertetangga? Pengaruh Dimensi Penerimaan Teknologi Mobile Phone Terhadap Kohesi Bertetangga," Proceedings of International Conference: Sustainable Built Environment in The Tropics: New Technology, New Behaviour? School of Architecture, Tarumanagara University, Jakarta, Indonesia, 2012.

[21] S. A. Brown and V. Venkatesh, "Model of Adoption of Technology in the Household: A Baseline Model Test and Extension Incorporating Household Life Cycle,” MIS Quarterly, Vol. 29, No. 4, pp. 399-426, 2005.

[22] V. Venkatesh, J. Y. Thong, and X. Xu, "Consumer Acceptance and Use of Information Technology: Extending the Unified Theory of Acceptance and Use of Technology," MIS Quarterly, Vol. 36, No. 1, pp. 157-178, 2012.

[23] M. Ogertschnig and H. van der Heijden, "A Short-Form Measure of Attitude towards Using a Mobile Information Service," in Proceedings of the 17th BledeCommerce Conference eGlobal Bled, Slovenia, 2004.

[24] S. Pahnila and J. Watsya, "Assessing the Factors that Have an Impact on Stickiness in Online Game Communities," in Proceedings of the 16th Pacific Asia Conference on Information Systems, Hochiminh City, Vietnam, 2012.

[25] F. B. Tan and J. P. C. Chou, "The Relationship between Mobile Service Quality, Perceived Technology Compatibility, and Users' Perceived Playfulness in the Context of Mobile Information and Entertainment Services," International Journal of Human-Computer Interaction, Vol. 24, No. 7, pp. 649-671, 2008.

[26] R. L. Walker, "Xenophobia," in Encyclopedia of Counseling, F. T. L. Leong, Ed. Thousand Oaks: SAGE Publications, Inc., pp. 1390-1391, 2008.

[27] J. Rydgren, "Xenophobia," in Encyclopedia of Multicultural Psychology, Y. Jackson, Ed. Thousand Oaks: SAGE Publications, Inc., pp. 483-485, 2006.

[28] P. Kivisto, "Xenophobia," in Encyclopedia of Social Problems, V. N. Parrillo, Ed. Thousand Oaks: SAGE Publications, Inc., pp. 1041-1044, 2008.

[29] M. A. Adler, "Xenophobia," in Encyclopedia of Race, Ethnicity, and Society, R. T. Schaefer, Ed. Thousand Oaks: SAGE Publications, Inc., pp. 1420-1421, 2008.

[30] J. M. George, "Extrinsic and Intrinsic Origins of Perceived Social Loafing in Organizations," Academy of Management Journal, Vol. 35, No. 1, pp. 191-202, 1992.

[31] F. Davis, "Perceived Usefulness, Perceived Ease of Use, and User Acceptance of Information Technology," MIS Quarterly, Vol. 13, No. 3, pp. 319-340, 1989.

[32] C. H. Liao, C. W. Tsou, and Y-C. Shu, "The Roles of Perceived Enjoyment and Price Perception in Determining Acceptance of Multimedia-on-Demand," International Journal of Business and Information, Vol. 3, No. 1, pp. 2752,2008 .

[33] C. S. Lin, S. Wu, and R. J. Tsai, "Integrating Perceived Playfulness into Expectation-confirmation Model for Web Portal Context," Information \& Management, Vol. 42, pp. 683-693, 2005.

[34] K. van der Veer, R. Ommundsen, O. Yakushko, L. Higler, S. Woelders, and K. A. Hagen, "Psychometrically and Qualitatively Validating A Cross-national Cumulative Measure of Fear-based Xenophobia," Quality \& Quantity, Vol. 47, No. 3, pp. 1429-1444, 2013.

[35] M. Fiedler, "Cooperation in Virtual Worlds," Schmalenbach Business Review (SBR), Vol. 61, pp. 172-194, 2009.

[36] A. I. Mockaitis, E. L. Rose, and P. Zettinig, "The Power of Individual Cultural Values in Global Virtual Teams," International Journal of Cross Cultural Management, Vol. 12, No. 2, pp. 193-210, 2012.

[37] N. Baumann, "Autotelic Personality," in Advances in Flow Research, S. Engeser, Ed. New York: Springer, pp. 165186,2012

[38] S. A. A. Jin, "Toward Integrative Models of Flow: Effects of Performance, Skill, Challenge, Playfulness, and Presence on Flow in Video Games," Journal of Broadcasting \& Electronic Media, Vol. 56, No. 2, pp. 169-186, 2012.

[39] D. Reid, "A Model of Playfulness and Flow in Virtual Reality Interactions," Presence, Vol. 13, No. 4, pp. 451-462, 2004.

[40] C. G. Lynch, "Companies Explore Virtual Worlds as Collaboration Tools," 2008.

[41] C. Lomas, M. Burke, and C. L. Page, "Collaboration Tools,” EDUCAUSE Learning Initiative, pp. 2, 2008.

[42] S. Y. Yousafzai, G. R. Foxall, and J. G. Pallister, "Technology Acceptance: A Meta-analysis of the TAM: Part 2," Journal of Modelling in Management, Vol. 2, No. 3, pp. 281-304, 2007.

[43] N. S. Nowlan, "Modeling The Effect of Perceived Ease of Use on Virtual Team Performance," Master's thesis, Department of Systems and Computer Engineering, Carleton University, Ottawa, Canada, 2011

[44] M. Anandarajan, M. Zaman, Q. Dai, and B. Arinze, "Generation Y Adoption of Instant Messaging: An Examination of the Impact of Social Usefulness and Media Richness on Use Richness," IEEE Transactions on Professional Communication, Vol. 53, No. 2, pp. 132-143, 2010.

[45] H. Gangwar, H. Date, and R. Ramaswamy, "Understanding Determinants of Cloud Computing Adoption Using An Integrated TAM-TOE Model," Journal of Enterprise Information Management, Vol. 28, No. 1, pp. 107-130, 2015.

[46] D. V. Parboteeah, K. P. Parboteeah, J. B. Cullen, and C. Basu, "Perceived Usefulness of Information Technology: A Cross-National Model," Journal of Global Information Technology Management, Vol. 8, No. 4, pp. 29-48, 2005.

[47] A. Simms and T. Nichols, "Social Loafing: A Review of the Literature," Journal of Management Policy and Practice, Vol. 15, No. 1, pp. 58-67, 2014.

[48] W. K. Gabrenya, Jr, B. Latané, and Y. E. Wang, "Social Loafing in Cross-cultural Perspective," Journal of CrossCultural Psychology, Vol. 14, No. 3, pp. 368-384, 1983.

[49] D. M. Heller, "Cultural Diversity and Team Performance: Testing for Social Loafing Effects," Master's thesis, University of North Texas, Denton, Texas, 1997. 
[50] K. Subrahmanyam, D. Smahel, and P. Greenfield, "Connecting Developmental Processes to the Internet: Identity Presentation and Sexual Exploration in Online Teen Chatrooms," Developmental Psychology, Vol. 42, pp. 395-406, 2006.

[51] M. F. Wright and Y. Li, "The Associations between Young Adults' Face-to-face Prosocial Behaviors and Their Online Prosocial Behaviors," Computers in Human Behavior, Vol. 27, pp. 1959-1962, 2011.

[52] I. Benbasat and H. Barki, "Quo Vadis, TAM?," Journal of the Association for Information Systems, Vol. 8, No. 4, pp. 211-218, 2007.

[53] A. Bajaj and S. R. Nidumolu, "A Feedback Model to Understand Information System Usage," Information \& Management, Vol. 33, pp. 213-224, 1998

[54] S. Dasgupta, M. Granger, and N. McGarry, "User Acceptance of E-Collaboration Technology: An Extension of the Technology Acceptance Model,” Group Decision and Negotiation, Vol. 11, pp. 87-100, 2002.

[55] K. Koffka, Principles of Gestalt Psychology. London: Routledge, 2013.

[56] J. Kelly and L. Kelly, An Existential-systems Approach to Managing Organizations. Westport: Greenwood Publishing Group, 1998.

[57] D. Forsyth, Group Dynamics (5th ed.). Wadsworth: Cengage Learning, 2009.

[58] R. Dotsch and D. H. J. Wigboldus, "Virtual Prejudice," Journal of Experimental Social Psychology, Vol. 44, pp. 1194-1198, 2008.

[59] M. Rinck, T. Rörtgen, W. G. Lange, R. Dotsch, D. H. J. Wigboldus, and E. S. Becker, "Social Anxiety Predicts Avoidance Behaviour in Virtual Encounters," Cognition and Emotion, Vol. 24, No. 7, pp. 1269-1276, 2010.

[60] L. R. Cruikshank, “Avatar Dreams: An Ethnography of Desire for the Virtual Body,” Master's thesis, Queen's University, Kingston, Ontario, Canada, 2001.

[61] M. Boberg, P. Piippo, and E. Ollila, "Designing Avatars," Proceedings of 3rd International Conference on Digital Interactive Media in Entertainment and Arts, DIMEA'08, Athens, Greece, pp. 232-239, 2008.

[62] B. E. Kolko, "Representing Bodies in Virtual Space: The Rhetoric of Avatar Design," The Information Society: An International Journal, Vol. 15, No. 3, 177-186, 1999.

[63] E. C. Baig, "Using Virtual Reality to Overcome Fear, Reduce Prejudice," 2015.

[64] J. H. Smith, "Trusting the Avatar," Games and Culture, Vol. 5, No. 3, pp. 298-313, 2010.

[65] M. R. M. Veeramanickam and N. Radhika, “A Smart E-Learning System for Social Networking," International Journal of Electrical and Computer Engineering (IJECE), Vol. 4, No. 3, pp. 447-455, 2014.

[66] F. B. B. Nasution and N. E. N. Bazin, "Adjusting ICT Capacity Planning by Minimizing Cyber Crime Effects in Urban Area: A System Dynamics Approach," International Journal of Electrical and Computer Engineering (IJECE), Vol. 4, No. 5, 2014.

\section{BIOGRAPHIES OF AUTHORS}

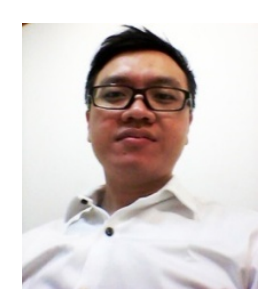

Juneman Abraham is the Faculty Member-Subject Content Coordinator (FM-SCC) on Community Psychology Studies at Bina Nusantara University (BINUS.ac.id); Secretary-General of Asian Psychological Association (APsyA.org); President of Association of Behavioural Researchers on Asians-Indonesia Chapter (ABRAIndonesia.org); Head of Organizational Compartment at Indonesian Psychological Association (HIMPSI.or.id); Certified Webmaster Professional (CWP) of the WOW Academy. Personal page: http://about.me/juneman

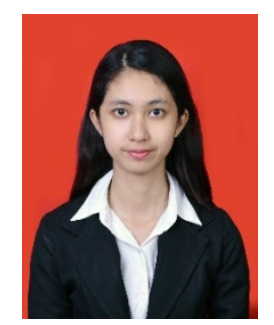

Melina Trimutiasari is an alumna of Psychology Department, Faculty of Humanities, Bina Nusantara University, Jakarta, Indonesia. 